\title{
THE INFLUENCE OF BRONCHODILATOR DRUGS ON THE PRESSURE-VOLUME RELATIONSHIPS OF FORCED EXPIRATION
}

\author{
BY \\ BRYAN H. GANDEVIA* AND F. J. PRIME \\ From the Department of Physiology, Institute of Diseases of the Chest, Brompton Hospital, London
}

(RECEIVED FOR PUBLICATION JULY 17, 1957)

Published work on the intrathoracic pressure and volume relationships during rapid maximal expiration has hitherto been confined to the study of healthy subjects and those with emphysema (Campbell, Martin, and Riley, 1956). It seemed to us that added light could be thrown upon the effects of bronchiolar obstruction if asthmatic patients were studied in whom the degree of obstruction could be lessened by treatment with bronchodilator drugs. We hoped thereby to understand more fully the mechanism of the increase in the volume of forced expiration which is usually observed following this treatment. To this end 10 patients with dyspnoea and wheezing associated with chronic bronchitis or asthma were investigated using a technique based on that described by Dornhorst and Leathart (1952).

\section{METHOD}

The investigations were carried out with the patients comfortably seated in an armchair. A narrow air-filled plastic catheter, passed through the nose into the oesophagus under surface anaesthesia, was used to conduct oesophageal pressure changes to an air-filled straingauge manometer. The output of this was recorded photographically using a double-beam cathode-ray oscillograph. The terminal $5 \mathrm{~cm}$. of the catheter was perforated by a number of small holes and covered by a thin air-tight rubber bag measuring $7 \mathrm{~cm}$. long by $0.5 \mathrm{~cm}$. wide when just full of air. Gas volumes were recorded and measured by means of a spirometer and kymograph identical to that described by Bernstein, D'Silva, and Mendel (1952). Time marks were inscribed on the volume and the pressure traces simultaneously from an electrical impulse generator which operated a stylus on the kymograph and interrupted the second beam of the oscillograph at the same time. Marks for orientating the two traces with respect to one another were made by means of a manually operated switch.

\footnotetext{
*Work undertaken during tenure of a Wunderly Travelling Scholarship from the Royal Australasian College of Physicians.
}

When the working of the apparatus was checked and found satisfactory the patient was instructed to deliver a "forced vital capacity" breath into the spirometer ; in this manœuvre the vital capacity must be delivered as quickly as the patient can possibly manage. Four recordings were made of his performance and these were analysed later.

Recordings were also made of four "relaxed breaths" in each of five patients. They were asked to inhale as deeply as possible and then allow their chests to collapse passively while connected to the spirometer. The relaxed breath resembled a deep sigh.

After the completion of these initial observations, the patients were given isoprenaline which they inhaled for one and a half minutes in the form of a $1 \%$ solution nebulized in a stream of oxygen from a Bright inhaler. Five to 10 minutes later a further set of recordings of forced vital capacity and relaxed breaths was made. The patients were already familiar with the methods we used and with what we required them to do, as well as with the subjective effects of inhaling bronchodilator drugs in mist form.

Calibration of the strain-gauge manometer was the final step in each investigation. We always found a very brief spike of high positive pressure at the beginning of each pressure tracing due to the inertia of the moving parts of the spirometer; we attempted to remove this by offsetting mouth pressure against oesophageal pressure in a differential strain-gauge. Although this was possible, we found that the adjustment of the time constants of the two sides of the transducer and conducting tubes was very difficult, and the resultant pressure curves were no different from the "single-sided " curves except for the absence of the peak. We therefore abandoned the use of the differential manometer and ignored the peak in the pressure trace when plotting the results.

From the tracings simultaneous values of volume and pressure were transferred to a pressure-volume diagram similar to the example shown in Fig. 1. By reference to the time marks the forced expiratory volumes at one and two seconds (F.E.V.1 and F.E.V.2) could be indicated on the diagram. Mean pressures exerted during the first one and two seconds were 


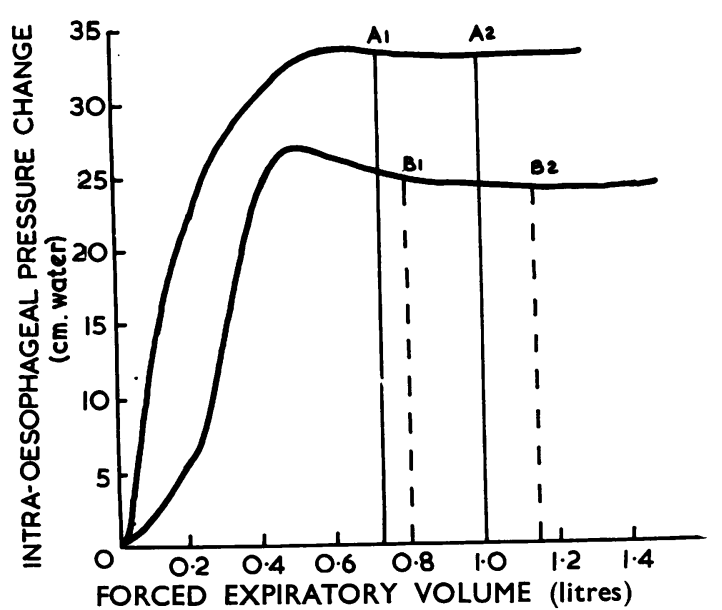

FIG. 1.-Specimen of two pressure-volume traces of forced expiration obtained from one asthmatic patient. Upper curve: before administration of isoprenaline aerosol. Lower curve: five minutes after isoprenaline. The ordinates $\mathbf{A}_{1}, \mathbf{B}_{1}, \mathbf{A}_{2}$, and $\mathbf{B}_{2}$ intersect the abscissa at the values for F.E.V.1 and F.E.V.2 in the two instances.

calculated from the area enclosed by the curve, the ordinate at the value of F.E.V.1 and F.E.V.2 and the abscissa, which was estimated with a planimeter; the area is a measure of the work done on the lungs, and division of this value by the corresponding volume gives the mean pressure during the first one or two seconds $\left(\overline{\mathbf{P}}_{1}\right.$ and $\left.\overline{\mathbf{P}}_{2}\right)$. From this brief description it should be apparent that, although the collection of the experimental data was simple enough, the working out of the results was tedious and time-consuming; for this reason alone the method is unsuitable for routine use.

\section{RESUlts}

These are summarized in Tables I and II. In seven of the 10 patients, the volume of gas expelled during the first second and the first two

\section{TABLE I}

MEAN VALUES AND RANGES OF MEASUREMENTS OF MORCED EXPIRATORY VOLUME AT ONE AND TWO SECONDS (F.E.V.1 AND F.E.V.2), PEAK INTRATHORACIC PRESSURE, MEAN PRESSURE DURING THE FIRST ONE AND TWO SECONDS $\left(\overline{\mathbf{P}}_{1}\right.$ AND $\left.\overline{\mathbf{P}}_{2}\right)$ AND F.E.V. $\overline{\mathrm{P}}$., IN 10 ASTHMATIC OR BRONCHITIC PATIENTS WITH WHEEZING DYSPNOEA BEFORE AND AFTER ADMINISTRATION OF

\begin{tabular}{|c|c|c|}
\hline & \multicolumn{2}{|c|}{ Mean Value (Range) } \\
\hline & Before Isoprenaline & After Isoprenaline \\
\hline 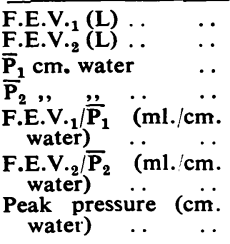 & $\begin{array}{c}1 \cdot 207(0 \cdot 60-2 \cdot 93) \\
1 \cdot 617(0 \cdot 83-3 \cdot 80) \\
37 \cdot 5(20-66) \\
40 \cdot 2(20-74) \\
32 \cdot 2(9 \cdot 1-146 \cdot 5) \\
40 \cdot 3(11 \cdot 2-211 \cdot 0) \\
54 \cdot 3(33-90)\end{array}$ & $\begin{array}{c}1 \cdot 526(0 \cdot 77-2 \cdot 93) \\
1 \cdot 931(1 \cdot 12-3 \cdot 44) \\
33 \cdot 9(12-61) \\
36 \cdot 6(17-69) \\
45 \cdot 0(12 \cdot 6-244 \cdot 0) \\
53 \cdot 2(16 \cdot 3-202 \cdot 0)\end{array}$ \\
\hline
\end{tabular}

TABLE II

MEAN VALUES AND RANGES OF MEASUREMENTS OF VOLUME OF “RELAXED" EXPIRATORY VOLUMES AT ONE AND TWO SECONDS (R.E.V. AND R.E.V.), MEAN INTRATHORACIC PRESSURE OVER THE FIRST ONE AND TWO SECONDS, AND R.E.V./F., IN FIVE ASTHMATIC OR BRONCHITIC PATIENTS BEFORE AND AFTER ADMINISTRATION OF ISOPRENALINE AEROSOL

\begin{tabular}{|c|c|c|}
\hline & \multicolumn{2}{|c|}{ Mean Value (Range) } \\
\hline & Before Isoprenaline & After Isoprenaline \\
\hline 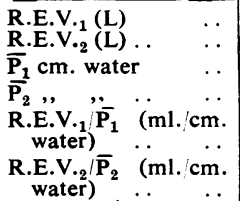 & $\begin{array}{c}0.918(0.73-1 \cdot 30) \\
1 \cdot 197(0.91-1.68) \\
13 \cdot 0(7-26) \\
12 \cdot 3(7-31) \\
70.7(26.9-186 \cdot 0) \\
97.3(32 \cdot 2-240.0)\end{array}$ & $\begin{array}{c}1.096(0 \cdot 76-1 \cdot 43) \\
1.467(1 \cdot 20-2 \cdot 12) \\
11 \cdot 6(8-16) \\
12 \cdot 3(5-21) \\
94 \cdot 5(40 \cdot 0-335 \cdot 0)\end{array}$ \\
\hline
\end{tabular}

seconds of expiration was increased after administration of the bronchodilator and the mean pressure applied during the first one and two seconds was lowered. The work of expiration, as measured by the product of mean pressure and volume change, was increased, in spite of the fall in pressure; also the volume of gas expired per unit of mean pressure was increased. In two of the remaining three patients the expired volumes were the same as before and in one there was a fall ; in all, however, the mean pressure was lowered; thus in these instances the work of expiration was decreased and the volume of gas expired per unit of mean pressure was raised.

The results obtained from the relaxed breaths (Table II) are qualitatively similar to the foregoing in that expired volume was increased in all cases, mean pressure lowered in three, raised in one, and unaltered in one. As a result values for work were increased in three and diminished in two whilst the volumes expired per unit of mean pressure were increased in all instances. The variation in the measurements in these observations is so wide that the average figures in Table II obscure the magnitude of some of the individual values. Thus, in one example, the volume expired per $\mathrm{cm}$. water mean pressure rose from $186 \mathrm{ml}$. to $335 \mathrm{ml}$. at one second and from $240 \mathrm{ml}$. to $402 \mathrm{ml}$. at two seconds. It should also be remarked that repeated measurements of relaxed breaths in a given patient differ more than do those of F.E.V. The changes occurring as a result of inhaling a bronchodilator aerosol, however, are qualitatively always the same.

In two patients the volumes of the relaxed breaths were nearly the same as the F.E.V., but the mean intrathoracic pressure level was twice as great during the forced breath as during the relaxed. 
Lastly, it was observed that the peak pressures reached during the measurement of the F.E.V. after isoprenaline were reduced by about $10 \%$ in all patients except one, in whom no change was seen.

\section{Discussion}

The principal reason why the maximum rate of gas flow from the lungs as measured by the F.E.V. is increased by administration of a bronchodilator is that airway resistance is diminished. This cannot account by itself for any increase in vital capacity, however, unless it is also postulated that some airways, previously closed, are opened. There is good evidence that in a forced expiration some of the narrower airpassages are closed by the abrupt increase in the pressure applied to the lungs and that gases are trapped beyond these in appreciable amounts; this occurrence is well illustrated by the greater volume of a vital capacity delivered slowly compared with one given as quickly as possible (Franklin, Michelson, Lowell, and Schiller, 1955). One explanation of our curious finding, that the maximum pressure after the bronchodilator was lower than before, would be that it is not possible for the lungs and thorax to collapse more quickly than some maximum rate no matter how low the airway resistance may be. This rate would be fixed by the tissue resistances of the thorax and its contents, the elastic forces and the power of the muscles involved in expiration at high rates. Since the pressure required to force gas through a tube is equivalent to the product of rate of flow and resistance to flow, it is conceivable that the reduction of airway resistance in the lungs could be sufficiently great to account for the observed fall in pressure. There is thus no need to conclude that the fall in pressure was due to the patient having made less than a maximum expiratory effort.

Turning now to the increase in work done during the first one and two seconds of forced expiration, we have found that this is increased after the bronchodilator drug mainly because of the greater volume of gas expelled. Since the mean pressure required to procure this increased volume is itself reduced, there is an increase in efficiency as measured by the volume exhaled per unit of mean pressure. If intrathoracic pressure changes are an index of the energy requirement of breathing a clear advantage accrues to the asthmatic patient by the use of bronchodilators, by adding measurements of intrathoracic pressure swings may be the reason for his sensation of easier breathing.

The experiments with relaxed breaths showed how much more efficient such breaths are from the patient's point of view than are forced breaths, and throw an interesting and significant light on the physiotherapy of pulmonary insufficiency in which "relaxation" (muscular and mental) is rightly emphasized.

From the practical clinical point of view we can conclude from our studies that a measurement of forced expiratory volume alone over one or two seconds is a sensitive indicator of changes in airway resistance produced by a bronchodilator drug; nothing of clinical value is to be gained by adding measurements of intrathoracic pressure to this relatively simple observation.

\section{Summary AND CONCLUSION}

The pressure-volume relationships of forced expiration in patients with bronchospasm, before and after the administration of bronchodilator drugs, show that the effect of the drugs is manifested not only by an increase in the volume of the forced expiratory volume but also by a lowering of peak and mean pressures achieved during delivery.

We confirm by our work that, for clinical use, measurements of expiratory volume during the first second of the forced vital capacity are sensitive indicators of changes in tissue and airway resistance in the lungs.

Our thanks are due to Dr. J. G. Scadding, who kindly gave one of us facilities to work in the Department of Physiology of the Institute of Diseases of the Chest ; also to the physicians of the Brompton Hospital, who helped us to find suitable patients for our investigation. Mr. P. K. Morgan, our chief technician, made our work possible by the exercise of his skill. Our chief gratitude, however, is to the patients themselves, who put up with the inconvenience we caused them with good-humoured understanding.

\section{REFERENCES}

Bernstein, L., D'Silva, J. L., and Mendel, D. (1952). Thorax, 7, 255. Campbell, M., Martin, A., and Riley, R. (1956). Personal communication.

Dornhorst, A. C., and Leathart, G. (1952). Lancet, 2, 109.

Franklin, W., Michelson, A. L., Lowell, F. C., and Schiller, I. W. (1955). New Engl. J. Med., 253, 799. 